\title{
"Decir todo: hacer política y ganar vida en cada libro" (Diálogo)
}

\author{
Eva Lazcano
}

\section{Alfonso Serrano}

\section{RESUMEN}

Proponemos una conversación entre una escritora metida a editora y un editor también librero. Dos vidas que se quieren entre libros. Como si la palabra lo pudiera todo. También tocar lo político. No lo político como posibilidad instrumental y reglada, sino como intervención consciente en nuestras formas de vida. Palabras conducidas por un objetivo concreto: tener efecto, económico, social, colectivo. Una conversación a dos voces sin acuerdos previos ni consensos oscilando entre una defensa radical del valor de los libros (donde el capital, simbólico o no, no es capaz de penetrar) y un cuestionamiento de afirmaciones y prácticas asumidas sobre su valor y potencial. La palabra obrará aquí indiscutiblemente ligada a quien la produce, a ese pueblo (¿sería este el término justo?) al que escritora y editor, o editora y librero, pertenecen. Y del que no quieren escapar. Una conversación en busca de materializar la cultura (¿o serían productos culturales?, ¿qué lejos quedaríamos de llamarlos entonces mercancías culturales?) y a quienes la fabrican, resituada como alianza entre destreza y materia por personas que sobre todo se han resistido a ser eslabón de otra cadena que no fuera la de hacer comunidad con quienes producen riqueza social. Una apuesta por hacer política desde la autonomía, desde el control de los medios de producción, desde el cuidado de saberes y prácticas socialmente heredadas. Como referencia: el crecimiento de una planta y la resistencia intergeneracional de las terrazas agrícolas. Un tomate, como un libro, como fruto de una conjugación de saberes todos situados. Riqueza social desde los libros. Libros que retornan valor a sus productores o que hacen común, por mucho fetiche que se cree al respecto. Libros situados, materialidades concretas que permiten un incontenible fresco donde además de pensamiento, creación y lectura, aparecen brazos y cajas, ojos y correcciones, espaldas y maquetas.

Eva: Leo el abstract como un meollo a desembrollar. Lo redactamos - ¿recuerdas?- coescribiendo frases. Meses después me desafía. Nos comprometimos a conversar; ¿podremos? Para querer hacerlo me he venido a un cuaderno viejo con un bolígrafo suave. Soy diestra en escribir a mano. Recuerdo un compañerito de Laia que en el cole cuando había que definir lápiz dijo: "instrumento de trabajo". Así me enseñaron a usarlo a mí también en el colegio. Manita para arriba, manita para abajo. Destreza muy material que me ha dejado una letra preciosa. Escribir es usarme en lo que me enseñaron a hacer. Una manita diestra muy trabajadora. Y lo sé hacer bonito. Bueno y pequeño. Poco a poco me he ido autorizando a poner esa destreza material al servicio de producir la riqueza que creo debo producir. Ahora bien, me pregunto, ¿ mi orgullo estajanovista es la originalidad mayor a la que podré aspirar? Ese trabajo 24/24 (en nuestra librería, en la editorial) que pospone tanto por años... ¿es todo a lo que podré aspirar? Quería esto que soy, no lo dudo. A menudo nos felicitan y huimos. A menudo, sin embargo, no podemos hacerlo bien y buscamos fuga o condescendencia. Difícil para un subalterno lograr plenitud y autonomía, pero... ¿lo podemos dejar de intentar? 
Alfonso: Hoy leíste un poema de mis 10 años, con letra redonda y escolar. Creció sin embargo esa letra para tumbarse, curvarse y llenarse de signos inventados. Una escritura casi en clave, indescifrable para el ojo externo. Quien sería editor hizo de sus letras un escondite mientras que quien escribiría las convertía en herramienta. ¿Qué conduce por un camino u otro? Cuando a posteriori calificamos una escritura o edición como política, ¿cómo entender realmente a lo que se refiere? A uno de los escritores marxistas más ortodoxos que conozco le leí algo así como que "cualquier avance de la sensibilidad es un avance revolucionario". Con eso en mente, ¿qué no sería político? Y si todo es político, ¿por qué reivindicar el término? Es probable, seguro, que entre libros propios y ajenos lleve más de un centenar de obras editadas en unos veinte años durante los que escribí al peso, reescribí y vendí frases a terceros antes de asumir en persona la responsabilidad por la circulación de obras. En ese tiempo mucho ha cambiado. Los impulsos, las convicciones y, sobre todo, los contextos, que hoy miro con infinita mayor desconfianza. Envejezco y veo en mi pasado afinidades que lo fueron solo por una profunda esencia irreflexiva; afinidades casi puramente estéticas que se disfrazaban de política. ¿Qué sería hoy, que diría hoy que es política y dónde estaría su contacto con la edición? Cierro los ojos y pienso. Dejo venir ideas. Vienen las erratas. Aquella tipa que nos chantajeaba veladamente con criticar su exceso en un libro, sí, defectuosamente editado. Ese canon que impone una forma de producción que sitúa su horizonte de posibilidad lejos de mi control. Ese canon que omite ante todo el contenido. Separar forma y fondo y criticar solo el primero: eso es política. Esas erratas y ese canon que hurtan de mí la posibilidad de controlar un medio de producción, que me condenan a trabajar a sueldo, a aceptar vender mis palabras y olvidar mis ideas, a entregar mis ojos a textos que quizás desprecio. Un mecanismo que excluye la autonomía, que me condena y llena de dependencias. Un primer atisbo para política.

Eva: Editamos a Lamarck, se lo conté a mi dentista que para mí es un tipo importante porque cuida mi estropeada dentadura con esmero y cariño, aun siendo yo pobre. Sobre la maravilla que fue editar "La filosofía zoológica" no tengo dudas. Sin embargo, el contexto nos negó la posibilidad de celebrarlo. Varios años después, no pierdo la esperanza. Quien nos trajo a Lamarck, me dejó esa obsesión por conjugar forma y función. Escribía Ortega y Gasset: "Flaubert decía: 'la forma sale del fondo como el calor del fuego' La metáfora es exacta. Más exacto sería aún decir que la forma es el órgano y el fondo, la función que lo va creando". Cada vez escribo más arriesgándome a caer de la frase. Me digo que la escritura ha de ser mi suelo. Pero no mi equilibrio. Mi equilibrio lo he de encontrar aventurándome a todas las frases que me queden por decir porque la vida se imponga. Nunca antes las ideas. Y peor aún sin mayéutica. Platón al menos dialogaba. Algunos libros, sus usos desatan un comportamiento orejera de burro. Demasiada gente lee para darse la razón, para vencer. Como si el conocimiento fuera un mérito o un puñetazo. Mal. Es como las erratas. ¿Cómo puede generar tanta crispación una errata? ¿Cómo puede alguien amenazarte con unas erratas? Para mí solo hay algunas cruciales y esas me ponen a investigar. Tú ya sabes que si algo odio de editar es consultar tanto la RAE, la maldita ortografía, cuando a mí de la lengua lo que más me interesa es la sintaxis, porque conjugo alterado desde niña y la etimología. El saber de los pueblos, nuestra raíz común, la de todas las lenguas reposa en el aljibe etimológico. Ahí supimos que a pesar del siglo XX la política no es lo contrario del mercado, es lo contrario de la idiotez. Me lo trajiste al corazón tú, ese saber. Me lo recordaste. Otra vez que necesitamos, como ahora, darnos hogar, calor, fuego. 
Alfonso: Miro desde el balcón reflejos en casa de la vecina. Mi vista, literalmente poco aguda, no sabe descifrar con qué se corresponden. Reflejos que oscilan, como los de esos CDs que muchos hortelanos despreocupados colgaban para asustar a los pájaros. Reflejos son también las ideas que actúan como faros en sociedad, que orientan el debate colectivo con señuelos. Podríamos pensar nuestra actividad editorial, y su vínculo con la política, desde la incidencia sobre esos señuelos, desde la capacidad que intentamos darnos para influir sobre ellos, cambiar un poco sus tonos o el foco de las luces que reflejan, señalar CDs colocados sobre otros árboles. Pero como ya decía, en ese sentido toda edición es política; la actividad editorial es la argamasa de una multitud de trabajos que son siempre decisión, elecciones, opciones que condicionan el mensaje, la concreción de sus formas y las vías de canalizarlo. Ninguna editorial esquiva eso. Elecciones ancladas en formas de entender lo colectivo que se trascriben sobre actos con incidencia pública y que merecen siempre, pues, el calificativo de políticos. Nuestra actividad editorial no sería ni más ni menos política que cualquier otra actividad editorial, pero si algo sigue agradándome en el adjetivo deriva no del reflejo que señalamos, sino del hecho de que somos nosotros quienes nos hemos alzado, nos hemos procurado -en precario- los medios, y aun condicionados, decimos: fijaos también en aquel otro reflejo. Si una victoria puedo señalar, una victoria en la que de verdad creo, es la de haberle quitado un trabajador cualificado a las máquinas de creación de señuelos que dominan el mundo editorial. Conseguí sustraer mi actividad a una mera venta de la fuerza de trabajo.

Elecciones, decía; pues sí, elecciones. Relación breve de elecciones políticas en el día a día de una editorial (política):

- la capitalina editorial Gamma consigue un acuerdo con el Instituto Beta del estado Y en América Latina. Con su financiación se construye una excelsa colección de pensamiento. Con mucho texto decolonial y ecologista. Financiada desde América Latina. Con dinero de arcas públicas alimentadas por el extractivismo. Dirigida por un madrileño. Editada desde Madrid. Con traductores casi únicamente españoles. Para la colección decolonial. Elección política.

- la distribuidora Zeta distribuye materiales militantes de diferentes editoriales por librerías afines. Han decidido no proveer de libros a las grandes centrales de compra, cabeza de lanza de un modelo económico que rechazan. No les venden nada. Nada, menos los libros de Zetaprima, editorial hermana, que difunde el mismo discurso, pero quiere también las ventas. ¿Hm? ¿Política?

- el grupo editorial madrileño Beta se interesa por un libro que iba a salir en una editorial vecina, más chiquita, con la que habían compartido espacio en un congreso dedicado en exclusiva a vías de cooperación editorial. Ante el interés por el libro, antiautoritario y cooperativista, encarga a sus abogados que detallen las vías en que sustraer al autor de sus acuerdos editoriales de la editorial chica. Competencia o colaboración. Política.

- el reputado escritor Fernández, de reconocido pasado izquierdista, escribe un manual sobre el sector del libro financiado de nuevo desde América Latina. El sector, amenazado, entre otros, por retos ecológicos y continuas deslocalizaciones, aplaude la novedad. El libro se imprime en China y desde allí se embarca en grandes cargueros que cruzan los océanos para llevar la buena nueva a puertos de todo el mundo. Política.

- una editorial francesa de nombre épico, de esos que entre entendidos remiten a tiempos míticos en los que las editoriales burlaban censuras bajo falso sello extranjero, se especializa en publicar 
pensamiento crítico, leído sobre todo por militantes izquierdistas. En el país de los agitados debates sobre el dumping social y el fontanero polaco, el mismo con el mejor convenio de imprentas conocido, el editor izquierdista imprime en Polonia. "El nacionalismo económico no me interesa", argumenta. Hm. Debate. Política.

- casa de tres plantas en el centro de una capital latinoamericana: un editor acoge en su domicilio una deliciosa velada con colegas del continente. Alguien menta al diablo: compras públicas. Y la velada se enciende. Todos coinciden en la necesidad de proteger la edición nacional contra la progresiva presencia de las editoriales españolas. ¿Españolas? Esa de la que habláis es propiedad de un grupo alemán. Y esa otra de uno italiano. Y hablar de nacionalidad, ¿de verdad es útil en todo esto? La división del grupo alemán que tenéis aquí en Solaria, publica casi exclusivamente autores de Solaria, desde sus oficinas en la capital de Solaria con editores de Solaria y libros impresos en Solaria; y ni siquiera exporta. El presidente del colectivo de editores de Lunaria, que en realidad es de Solaria, publica solo traducciones e imprime en China, se rebela contra los matices y reclama el criterio de nacionalidad en la compra pública. Mientras, el presidente de Danone sigue teniéndolo claro: "la única nacionalidad de Danone es Danone". Hm. Debate. Política.

- más compras públicas: crisis y pandemia. Caos en el sector. Riesgo de impagos en cadena y, de repente, una bocanada de aire: una gran compra pública se reparte por casi todas las librerías de la ciudad. Magnífico. Un alivio. Los libros hay que servirlos en la quinta planta de un edificio sin muelle de carga, sin espacio para aparcar y con solo un ascensor. Sus muertos. Las cuentas se salvan, pero se revientan todas las espaldas, entre ellas la mía. ¿Todas? No... para; deja la caja y mira: la mitad de las librerías han subcontratado la infame entrega a un colega latino que cobra tarifa fija. Luis Antonio se deja la espalda por una miseria mientras las librerías descansan y respiran. Política.

- noche en un bar (cosas de esas de antes de la pandemia): conversación sobre libros y zas, la gran coincidencia, un amigo de mi interlocutor, latinoamericano, está con ganas de traducir un mismo libro que llevo queriendo editar más de un año. Tiramos del hilo y se suma una editorial de allá. Compramos derechos y nos ofrecen un acuerdo: traducimos nosotros y compartimos costes. Hago cálculos y argh, deslocalizaciones, política: si lo hacemos con ellos cuesta solo un cuarto de lo que nos costaría hacerlo nosotros.

\section{Cuestionarse.}

Mirar donde todos hacen como que no miran.

Política.

No sólo en el árbol que señalas o en la luz que reflejas. También en los materiales por los que optas como superficie para el reflejo, también en los cuerpos que fabrican, transportan y colocan la superficie que refleja. Política en los cuerpos. En mis manos. En las cajas. En el transportista.

Alianzas ya no tanto con editores, sino con el del reparto. Viva el del reparto. 
Eva: No sé si te acuerdas de Z, nuestro obrero ejemplar. Uno de los más activos de la lucha de Y. Sabes, como yo, que, con el dinero de su victoria sobre el capital, se abrió una casa de apuestas. Casi me muero cuando me lo contó... Somos monos con escopeta. Tal cual. Tengo un especial odio a las adicciones. Las activaciones de todo tipo de agentes de enajenación, me sacan de quicio... Te lo digo porque el que tanto "avivas" del reparto, no sabemos cuánto tiene de little expoliador. Quizá en su cadena trófica sea completamente bulímico y coma cerdo barato todos los días. (Saco el cerdo porque no puedo olvidar una fotografía ganadora de algún premio que vi el otro día al azar. El cerdo en cuestión yace, convertido en zombi, con los ojos inyectados en sangre, sucio, asqueroso, repugnante, y tan ser vivo, $\tan$ conmovedor, $\tan$ doliente... que se me ha instalado en el cerebro, y quizá sea de las fotos que me pase a quedar para siempre, de esas diez finales... de cuando te mueres. Como la del cuervo al lado de la niña famélica esperando a comérsela. De esas fotos que te aseguran desde dentro del oído: ¡los humanos merecéis la extinción, querida!).

Es imposible salvar a nadie, tampoco es lo que pretendo. Merecer salvación. Ni nada así de cálculos de justicia rampante. Entre las iniciales estamos también los dos... o deberíamos estar. No sé desvelar todos tus referentes. Pero sí sé que a mí lo que me hace querer vivir cada día es un constante ejercicio de uso de mis órganos para revelar su potencia, la que le permita disfuncionar pero también hacer algo bueno. Algo menos genocida. No se trata de quererme, se trata de hacer posible que yo pueda quererlo todo. Y cuanto más, mejor, para que nada me dé miedo, para que no me tiente la zafiedad, el narciso, lo espurio. ¿Qué roñería nos ganó como civilización para acabar haciéndonos sádicos ejecutores de una tendencia compulsiva a comer carne?

El dolor, hacer del corromperse o infringir dolor algo estructural no podemos tolerarlo. Jamás. Deberíamos tener claro que tenemos que hacer justo lo que nos lo impida. Toda esa maldita asunción de ciertas normas. Como esa, que no parece genocida, de editar miles de libros para hacerse ver porque, en caso contrario, no vendes, Amazonía mediante. Cada autor que no asegura que su libro sea impreso en la justa medida es un depredador. Pero la gran mayoría consiente. Se instalan en el reino de las ideas, en las torres de marfil que las hay para todos los gustos más o menos humanistas, más o menos comunistas, y venga y dale a abstraerse de su responsabilidad en la cadena trófica. La materia deja de vibrar. Y lo que tú decías, escritor comunista, pagado por gran grupo editorial, señala a todos los comunistas del mundo lo que han de hacer y pensar, mientras espera a ser pagado por el gran capitalista del mundo. Trampantojo, tras trampantojo hasta llegar al del dinero y la fama. Y los poderes mágicos que se le da. Dinero, como si pudiera ser más importante que cualquier otro papelucho que se acumula en mi mesa.

Todo eso yo lo he estallado. Así cada miaja, cada pingarata, cada "nadie" que nombraba mi abuelo: incluido Z, su lucha obrera victoriosa contra la multinacional, su casa de apuestas y su victoria contra el señor malote de la multinacional...: ¡lo quiero todo! Al señor malote lo que hago es procurar no encontrármelo para no tenerle que querer también porque los expoliadores capitalistas son conservadores, acaparadores y mandones de todo. Y, sí, para mí la política también es defender mi autonomía. Ya tengo más que claro que requiero de toda mi atención para atinar en lo que he de hacer... que es tanto, es todo. Todo por hacer.

Porque sí, porque no hay acierto sin comunidad para la realización de nuestros bienes materiales. Y como seres sociales que podemos cuidarnos nos están bombardeando casi todos los vínculos. Pero necesitamos poder contarnos, decirnos, leernos, hablarnos. Dejar de vivir en un monólogo interior. Y últimamente con las redes, los algoritmos, las crispaciones, la 
polarización, se está poniendo mal, pero fatal lo de poder meditar y hacer con otras y otros, con hondura y libertad.

Por eso, gracias a ti, edito y vendo libros. Y, gracias a atender a mi necesidad, escribo. Porque al final son el lugar donde el ejercicio del saber para hacer, se realiza aún. Y me armo de valor para hacerlo cada día con la brutal inocencia con la que juegan los y las niñas. Me atrevo a decirlo todo. Animar a cualquiera a leer pidiendo solo atención. Amor. Porque no nos damos cuenta, pero cada vez nos decimos menos y nos arriesgamos menos a discutir. Y necesitamos conflicto. Pero para eso tenemos que respetar a quien cuestionamos. Mi enemigo concreto es quien incita o fuerza a un uso de los órganos que yo uso para activar la vida, justo para desperdiciarlos o pervertirlos de cualquier manera. Por eso odio a todo tipo de explotador, tanto como a cualquier adoctrinador, moralista, incoherente y vano que acapara los usos de la palabra para opacar potencia.

$\mathrm{Y}$, finalmente, nos recuerdo que, si bien hay personas malas y palabras malas, tampoco es para tanto... más allá de nuestro propio acierto, hay mucho, casi todo que aún no lo sabemos, que no depende de nuestra voluntad, que no vamos a poder controlar, que no entendemos... y conviene la modestia y la ternura para con nosotros y nosotras mismas.

Por eso me gustan los libros que sobre todo son enormes exposiciones de un límite a compartir. Me gustan los que dicen para hacer. Y hay muchos así que te abren en la cabeza una posibilidad de vivir de otra manera, que te montan sobre una nueva pregunta. Lo cierto es que siento que en nada mitifico los libros... sí sé que la gente que rodea la palabra es amable. En la librería lo percibo constantemente.

Soy mala librera, y con todo, al terminar de trabajar allí lo poco que voy, suelo volver contenta. El uso del lenguaje, la discusión para enseñarnos a ser humanos. La palabra como una destreza humana y el libro como la materia que mejor la pone en juego, sin duda. Eso es para mí la política. Aprender con otras y otros a usar lo que nos es necesario, para abotargarnos menos, para enajenarnos menos, para desperdiciarnos menos. Hacer uso del pensamiento, la afectación, la meditación, el diálogo, incluso la discusión, la contradicción, la bronca... para atinar mejor cómo vivir más pleno, más potente, más generosamente.

A menudo me viene la imagen del libro ideal como aquel que abre un hueco en el saber donde poder meter lo que aún no encontró cabida. ¿Has pensado alguna vez tú qué libro te gustaría publicar? ¿Y escribir? ¿Y cuál quisieras leer? Te lo digo porque he vuelto a releer nuestro texto y yo sí sé lo que debo contar y todavía no me atrevo ¿sabes? No me atrevo. Y ahora ya sé que mi manita no va a funcionar eternamente. Que me queda no tanta vida. Ni tanta fuerza, ni tanta energía. Qué quizá acabe por no hacer lo que tengo que hacer. ¡Qué violento para una subalterna lograr autonomía y plenitud! Cuánto todavía por hacer. ¿Cuéntame anda qué sería exactamente lo que quisieras leer, escribir y editar?

Alfonso: Quiero libros como aquel, bicolor, que de tan joven me enseñó a identificar no solo el rencor de clase sino de su potencial autodestructivo; o como este otro sobre los pechos que nos llegó hace poco y que sana la mirada descubriendo "cuerpos cual paisajes". Libros que ensanchan la potencia, que abren el horizonte, que amplían el terreno fértil para los sueños, que nos hacen crecer. Como aquel, destinado a ser leído por pequeños y mayores al tiempo, sobre tomates, gusanos y huertas. Libros capaces de ser compartidos, que no pasan inapercibidos, que fueron concebidos con propósito y que obran en nuestras vidas de forma duradera. Libros que son también produc- 
to, que no pretenden borrar el rastro de trabajo que les dio forma, que son capaces de responder no sólo a un qué sino a un porqué y un cómo. Qué cuentas, por qué lo cuentas, cómo lo cuentas, quién lo cuenta. Un amigo me recordaba hace poco que el libro es uno de esos productos, pocos, imagino, cuyo consumo en realidad cuesta más que su compra (obviaré aquí por un momento los conflictivos implícitos de la equiparación de 'consumo' con lectura y la medición econométrica del tiempo). Sea cual sea la forma de medirlo, el tiempo invertido en leerlos será prácticamente siempre superior al empleado: el acto aislado de su compra. Lo fundamental que pedimos pues a un lector no reside en un precio de compraventa, sino en un tiempo y una atención ubicados en vidas cargadas y finitas. Si algo, pues, ha de definir -en mi opinión- aquello que aún puedo seguir queriendo llamar edición política, es el esfuerzo por enriquecer y mantener las respuestas sobre el porqué, el cómo, el quién, incluso el para qué. Una carga extra de reflexividad sobre el propio acto, si se quiere. Un esfuerzo por desvelar motivaciones, procesos y efectos. Un reconocimiento explícito de la falta de inocencia que no puede sino caracterizar actividades (escritura, concepción, edición, diseño, fabricación, distribución, promoción) que tanta planificación requieren y tantísimas horas consumen. La gran diferencia pues de la edición política respecto al resto residiría pues en la ausencia de mecanismos de ocultación respecto a esos procesos. La falta de colaboración con los mecanismos de fetichización de nuestra mercancía. El resto de elementos y territorios (imprentas, transportes, librerías, bibliotecas, tendencias económicas, impactos ecológicos, variaciones tecnológicas, contextos culturales, formas administrativas, marcos económicos y legislativos...) no pueden sino ser compartidos con el conjunto de la edición. Sin duda, la forma de conjugar todos los elementos que inciden sobre nuestro campo varía en función de las elecciones y estrategias de cada cual. Pero ninguno es exclusivo. Nada hay de diferente en una edición que podamos llamar política salvo el desvelamiento expreso de sus motivos. Desnudez, nada más que eso.

Eva: No llegamos a las 5000 palabras que nos pidieron. Sacarnos palabras cuesta. En mi caso, sé bien que aun odio mi escritura. A mi clase baja, a ese pueblo que soy, nos han enseñado a temer expresarnos con libertad y cuando no lo pudimos evitar, acumulamos desprecio y agresiones. Dañarnos lo que decimos, despreciar nuestros textos, duele más de lo que parece. Los ataques a nuestro gusto, a lo que consideramos más propio, son grilletes viscerales. Se dice que a las clases bajas no les importa la cultura y yo creo que es justo lo contrario. Darías la vida por una canción. De modo que cuando callamos es bueno apreciar que tenemos motivos. Con el tiempo, para consuelo de mi rabia de clase, he aprendido que a las clases altas les dan libertad formal. En los contenidos de lo decible es donde están más limitados los poderosos. Porque los ricos necesitan conservar y no soportan la derrota. Yo voy liberándome, aunque para terminar releo el texto y reconozco que escribo de forma poco explicativa, incluso poco incluyente de lector alguno. Dado el poco aprecio que ha recibido mi escritura, he acabado escribiendo, exclusivamente, para saber bien lo que necesito hacer. No valoro ser leída. Incluso diría que escojo lectora. Y sobre todo quiero que la palabra circule. Quiero hacer escribir, hacer hablar, hacer leer, hacer escuchar. Hacernos bien con la lengua, las palabras, los libros. Y en La Oveja Roja, para eso he tenido una libertad que te agradezco. La libertad de escribir libros transcribiendo las palabras que nos confiaron. Y desde ahí bendigo Somos CocaColaenLucha, Somos las que estábamos esperando, no porque crea que contienen toda la razón, sino porque hacen algo de justicia. Bendigo también esas escrituras de encargo que nos han tomado escrituras de demiurgos, orfebres anarquistas como Enrique Falcón, 
con su Sílithus. Ese libro, tú y yo sabemos que es un milagro, y nos va a acompañar hasta nuestra muerte como un objeto físico que además tendremos repetido. Un milagro reproducible. Eso es a veces un libro. Un milagro largo. Y sí, hemos editado libros realmente buenos. Y, bueno, nos ha costado, pero finalmente hemos sobrevivido lo suficientemente fuertes como para no querer tener el poder de imponer nuestra ganancia, porque no le tenemos miedo alguno a perder. Tampoco a ganar así cuando Brigitte vendió tantísimos libros, o Valentín o Juan Carlos, lo que vivimos fue una fiesta de encuentros, una pura celebración democrática. Y bueno, lo voy a ir dejando ya... ahora mismo ya llevamos 4500 palabras. Releo lo escrito y me emociona, no es seductor, es generoso: siento que para los dos se ha tratado de compartir lemas. Las consignas de nuestras actuaciones librescas hasta ahora. No para que las siga nadie. Más bien en pos de "esa desnudez". Nos querían tapadas y enmudecidas pero nos hemos escapado de toda prisión. Como Blas de Otero, "yo doy todos mis versos por un hombre en paz". No necesitamos agarrarnos ni a nuestras consignas. No. Las ponemos en circulación, son vehículos, útiles, para responder a esta invitación a escribir sobre lo que hacemos. Sumando a nuestra conversación. Uso el hashtag \#comando_libro, su web y la de Contrabandos, por si alguien de quien nos ha leído quiere también sumarse a nuestra discusión de décadas. No tenemos más convicción que la de alentar la vida con palabras. No rehusar de usar mi lengua, nuestra lengua. Ese es nuestro suelo compartido y ahí os esperamos.

Alfonso: Mi suelo es mi trabajo. Y mi trabajo, que es hoy esta edición que acepto se adjetive como política, es pura rebeldía, o mejor, pura liberación. Liberación de la materia que alimenta mis sueños, liberación de la vista miope que dibuja cuadros con estrellas, liberación de la potencia que todos atesoramos y que solo a golpe de canon (y respaldo de cañón) queda amortiguada. Repetiría una y mil veces la profunda rabia que despierta la fetichización que iguala mi trabajo con el del hijo de los marchantes de objetos robados por los nazis, el juego de manos que borra el rastro de sangre de las acumulaciones económicas y culturales que posibilitan el acceso a la producción de unos y dificultan sobremanera la de otros, la rabia contra la solo teórica separación que permite canonizar formas y ocultar al tiempo contenidos. 